\title{
INTEGRATED USE OF MAGNETITE IN ENVIRONMENTAL PROTECTION MEASURES
}

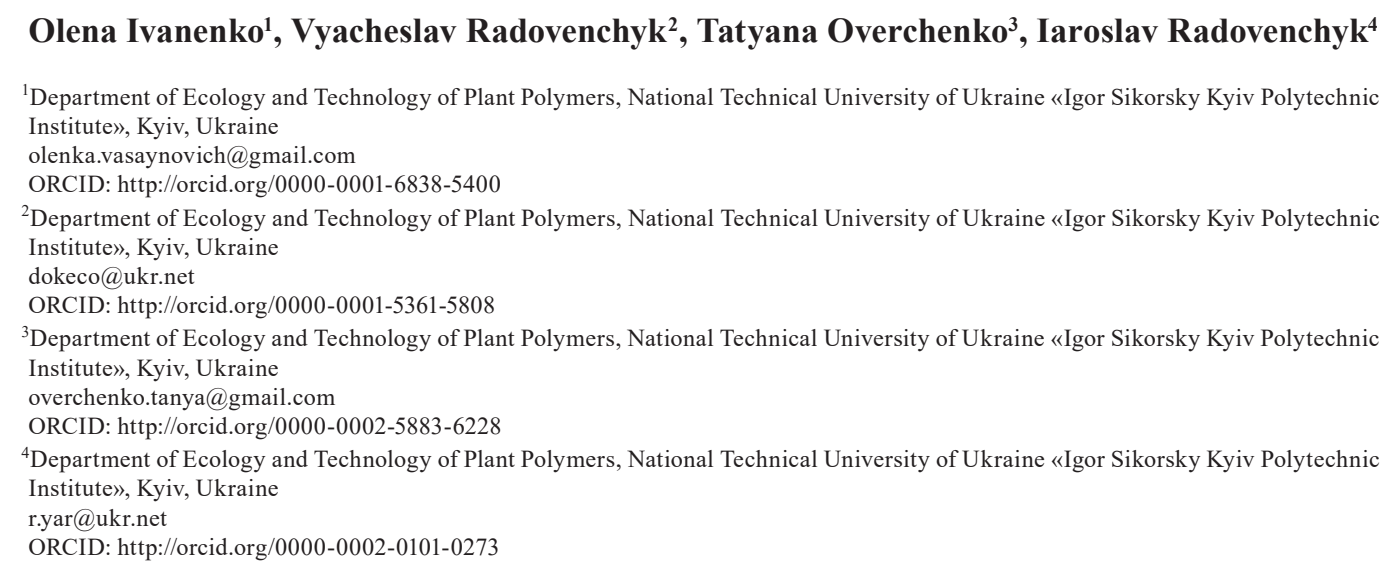

ARTICLE INFO

Article history:

Received date 23.09.2020

Accepted date 20.10.2020

Published date 30.10.2020

Section

Waste Management and Disposal

D O I

$10.21303 / 2313-8416.2020 .001462$

KEYWORDS

iron-containing solutions

ferrite method

magnetite

flue gases

carbon monoxide

build-up method

catalyst

red lea

\section{A B S T RACT}

The object of research: magnetite obtained by using the ferritic method for the purification of iron-containing solutions.

Problem to be solved: a comprehensive solution to the problem of using magnetite, obtained as a result of using the ferrite method for purifying iron-containing solutions, as a catalyst for the oxidation of carbon monoxide and its further utilization in the production of building materials.

The main scientific results: it has been shown that the magnetite precipitate formed during the processing of pickling solutions by the ferrite method can be used as a cheap, affordable and effective catalyst for the oxidation of carbon monoxide from flue gases of industrial enterprises, the disposal of which after long-term use does not create problems due to its stability and inertness.

Field of practical use of research results: the use of the ferrite method in the purification of pickling solutions of metallurgical enterprises provides not only an increase in the efficiency of water purification, but also leads to the introduction of waste-free technology. The decisive factor will be the use of magnetite as sludge of the use of ferrite technology to solve the problem of reducing flue gas emissions from the production of electrodes for the metallurgical industry, which include toxic carbon monoxide.

Innovative technology product: waste-free technology for the processing of pickling solutions by the ferrite method with the formation of a product with magnetic and catalytic properties, further processing of which consists in using red lead iron as a pigment in the production of building materials.

Scope of the innovative technology product: oxidation of carbon monoxide from industrial flue gases, followed by the use of red lead as a pigment.

(C) The Author(s) 2020. This is an open access article under the CC BY license http://creativecommons.org/licenses/by/4.0).

\section{Introduction}

\subsection{The object of research}

Magnetite obtained as a result of the use of the ferrite method for the purification of iron-containing solutions.

\subsection{Problem description}

To date, the pace of development of metallurgical production in Ukraine is significantly ahead of the development and implementation of the latest technologies for wastewater treatment and processing of formed sludge. The widespread introduction of reagent cleaning technology has led to the accumulation of millions of tons of liquid waste in the environment, the cost of which 
increases annually. In addition, existing disposal methods do not always provide reliable isolation of sludge from the environment [1]. The use of the ferrite method even at already existing treatment facilities can provide not only an increase in the efficiency of water treatment, but also lead to the introduction of waste-free technology. Only such technology can be considered environmentally friendly if its application does not lead to environmental pollution with harmful residues. In the event of the formation of such residues, they must be converted into substances that are safe for the biosphere, or even better, reused after additional processing in other technologies. According to the authors' conclusion [2], the operating costs for the implementation of the ferrite method are slightly higher than when using the traditional reagent method. Therefore, it may turn out that the regeneration of magnetite is not economically viable. Only with the use of large-scale, continuously operating enterprises can this process become feasible.

\subsection{Suggested solution to the problem}

As studies show [3,4], the use of ferritic sludge has a good potential for environmental use as a valuable raw material for catalysts for $\mathrm{CO}$ oxidation. The total number of applications of nanoferrite technologies for catalytic purposes is still relatively small; therefore, the development of effective solutions can become an ideal research niche for the introduction of ferritic nanomaterials into production for the neutralization of flue gas carbon monoxide [4]. After being used as an oxidizer with a low sensitivity to catalytic poisons, the direction of disposal of the residues of such technologies is determined, first of all, by their toxicity. The value of ferrite as a promising material from the point of view of environmental catalysis is undeniable, since if it is used, there will be no problems with its operation and utilization, since ferrite is not toxic and has limited biodegradability [3].

Despite the fact that in Ukraine there are several industrial plants using the ferritic method of water purification, there are practically no data on the feasibility of its industrial application, given the further handling of the formed sludge. The essence of the ferrite method for purifying iron-containing solutions is to treat them with appropriate reagents, which, upon further regulation of the conditions in the solution, cause the formation of highly dispersed magnetite particles with magnetic properties. When synthesizing magnetite, it was found that the maximum magnetic properties are possessed by particles obtained with the ratio $K=\left[\mathrm{Fe}^{2+}\right] /\left[\mathrm{Fe}^{3+}\right]=0.5$, that is, in accordance with the ratio in magnetite of natural origin, contains $31.03 \% \mathrm{FeO}$ and $68,97 \% \mathrm{Fe}_{2} \mathrm{O}_{3}$. Obviously, with such a ratio, magnetite has the most ordered structure [5]. Magnetite is a fairly stable compound [6], insoluble in water either at 20 or at $100^{\circ} \mathrm{C}$. It is also insoluble in ethyl alcohol, diethyl ether and reacts weakly with acids. When heated in air to $150^{\circ} \mathrm{C}$, magnetite transforms into iron oxide $\mathrm{Fe}_{2} \mathrm{O}_{3}[1]$.

The process of obtaining magnetic particles of high dispersion from a mixture of divalent and trivalent iron ions by precipitation with alkali with constant stirring is currently well developed and is of industrial importance. Despite the fact that the process of magnetite synthesis from a mixture of iron salt solutions is rather fast, the influence of various factors on its course remains significant. In this regard, it is possible to obtain precipitation with strictly planned characteristics in advance only if the corresponding conditions are strictly observed. However, the mechanisms of formation of magnetite particles and their aging have not yet been sufficiently studied in this case. The main reason here is the complexity of ferritization processes and their dependence on many technological factors. Of great importance in ferritization processes is the reagent used for precipitation. In the series $\mathrm{KOH}, \mathrm{NaOH}, \mathrm{LiOH}, \mathrm{NH}_{4} \mathrm{OH}$, the magnetic properties of the deposited particles increase [7]. Magnetite precipitated with ammonia has the maximum magnetic properties. In order to accelerate the process and improve the quality of the precipitate, it is necessary to maintain the ratio between ferrous and ferric iron as 1:2, and sedimentation should be carried out at $\mathrm{pH}=9-11$ [8]. In real technologies, the amount of alkali is always taken in excess compared to the stoichiometric one. Therefore, when obtaining magnetite by this method, the $\mathrm{pH}$ of the mixture is controlled. In most real technologies, these boundaries are significantly narrowed and, of course, $\mathrm{pH}=9-10$, which is associated with the need to comply with the total content of anions in the treated waters at levels below the MPC.

The aim of research is to substantiate the complex use of magnetite obtained by using the ferrite method of water purification in a closed cycle in various environmental technologies. 


\section{Materials and methods}

Magnetite was obtained by chemical condensation. For the synthesis of magnetite particles, weighed portions of $\mathrm{FeSO}_{4} \cdot 7 \mathrm{H}_{2} \mathrm{O}$ and $\mathrm{FeCl}_{3} \cdot 6 \mathrm{H}_{2} \mathrm{O}$ salts with a total concentration of iron ions of $5 \mathrm{~g} / \mathrm{dm}^{3}$ at a concentration ratio $K=\left[\mathrm{Fe}^{2+}\right] /\left[\mathrm{Fe}^{3+}\right]=0,01-3$ were dissolved in distilled water and a temperature of $30-35^{\circ} \mathrm{C}$, the resulting mixture was treated with an ammonia solution until a $\mathrm{pH}$ value of 9.5-10 was established. As a result of such treatment, fractions of magnetite were formed in the solution in accordance with the reaction:

$$
\mathrm{FeSO}_{4} \cdot 7 \mathrm{H}_{2} \mathrm{O}+2 \mathrm{FeCl}_{3} \cdot 6 \mathrm{H}_{2} \mathrm{O}+8 \mathrm{NH}_{4} \mathrm{OH} \rightarrow \mathrm{Fe}_{3} \mathrm{O}_{4}+\left(\mathrm{NH}_{4}\right)_{2} \mathrm{SO}_{4}+6 \mathrm{NH}_{4} \mathrm{Cl}+17 \mathrm{H}_{2} \mathrm{O}
$$

The resulting suspension of magnetite particles for "maturation" was left in the mother liquor for 30 minutes, after which the solid phase was separated by decantation, washed with distilled water until neutral and dried at room temperature with access to atmospheric air.

Measurements of the magnetic characteristics of the deposit were carried out using the method [9]. The diagram of the device for measuring the relative magnetic characteristics is shown in Fig. 1.

The operation of the device is based on measuring the increase in the inductance of the coil when a sample of a magnetite suspension is introduced into its working volume. The growth rate was determined by the formula:

$$
L=L_{i}-L_{o},
$$

where $L_{i}$ - the inductance of the coil when a test tube with sediment is inserted into it; $L_{o}-$ the inductance of the coil before the test tube is inserted into it.

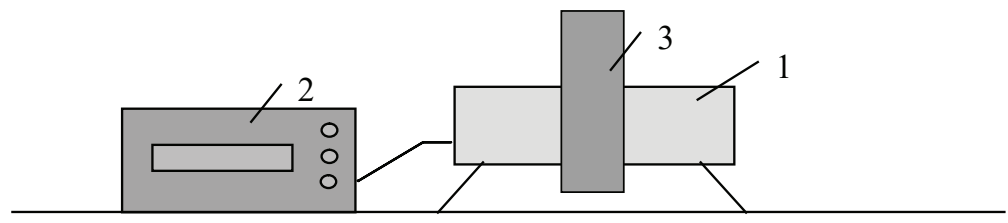

Fig. 1. Diagram of the device for measuring the relative magnetic properties of colloidal solutions: 1 - inductance coil; 2 - AC bridge; 3 - test tube with magnetite suspension solution

The relative magnetic properties of the sediment were calculated using the formula:

$$
\chi / \chi_{\max }=L / L_{\max },
$$

where $L-$ an increase in the inductance of the coil of a separate measurement of this series of studies when a test tube with sediment is introduced into it; $L_{\max }$ - the maximum increase in the inductance of the coil according to the measurements of this series of studies when a test tube with sediment is introduced into it.

At all stages of research on the presence of magnetic properties, the actual value of the Cochran criterion was greater than the calculated one.

The granulometric composition of the solid phase was determined by the photoelectric method according to [10].

When studying the processes of washing from excess magnetite salts obtained by chemical condensation, the sediment was washed several times with distilled water, the volume of which was equal to the volume of the separated mother liquor with a proportional decrease in the amount of precipitate taken for analysis, to a neutral reaction, and dried at room temperature with access to atmospheric air.

The size of the synthesized magnetite particles was increased by growing layers by mixing these particles with a similar dose of the initial solution of iron ions and re-precipitating the suspension with alkali. The granulation of the magnetite suspension by freezing was carried out at a temperature of $-10{ }^{\circ} \mathrm{C}$. The thawing process proceeded until the liquid phase completely drained off at a temperature of $20^{\circ} \mathrm{C}$. 
To study the conversion of $\mathrm{CO}$ to $\mathrm{CO}_{2}$ using catalysts based on magnetite, let's use the laboratory device shown in Fig. 2. The device consists of a heat chamber 4, made of a stainless steel pipe 6 and a ceramic pipe 7, inside which a heating element is located 3. A system for maintaining a given temperature during the experiment, including thermocouples 5 and a temperature controller 8 . By adjusting the duration of the heating element 3 , the system maintains the set temperature. A sample of the catalyst under study was poured into a cylindrical container 2 and fixed in a metal tube 6 in such a way as to exclude the passage of a model gas mixture past the catalyst. The volumetric velocity of the model gas flow was changed in the range of $1-5 \mathrm{dm}^{3} / \mathrm{min}$ and was measured using gas flow meters 9 . During the experiment, using a gas analyzer 1, the content of the components of the gas mixture at the inlet and outlet of the heat chamber was determined. In some cases, molecular nitrogen was additionally used as an inert gas. The concentration of the components of the gas mixture before and after the reaction was analyzed with an accuracy of $\pm 20 \mathrm{ppm}$ or $\pm 5 \%$ of the measured values. To stabilize the conditions of the experiment, before carrying out the catalyst, the proportions of the catalyst were calcined without oxygen for 2 hours at a temperature of $450{ }^{\circ} \mathrm{C}$, determining the weight loss of the catalyst. The studies were carried out in the temperature range $200-400{ }^{\circ} \mathrm{C}$. The molar fraction of carbon monoxide in the model gas mixture at the reactor inlet was maintained at 1.1.

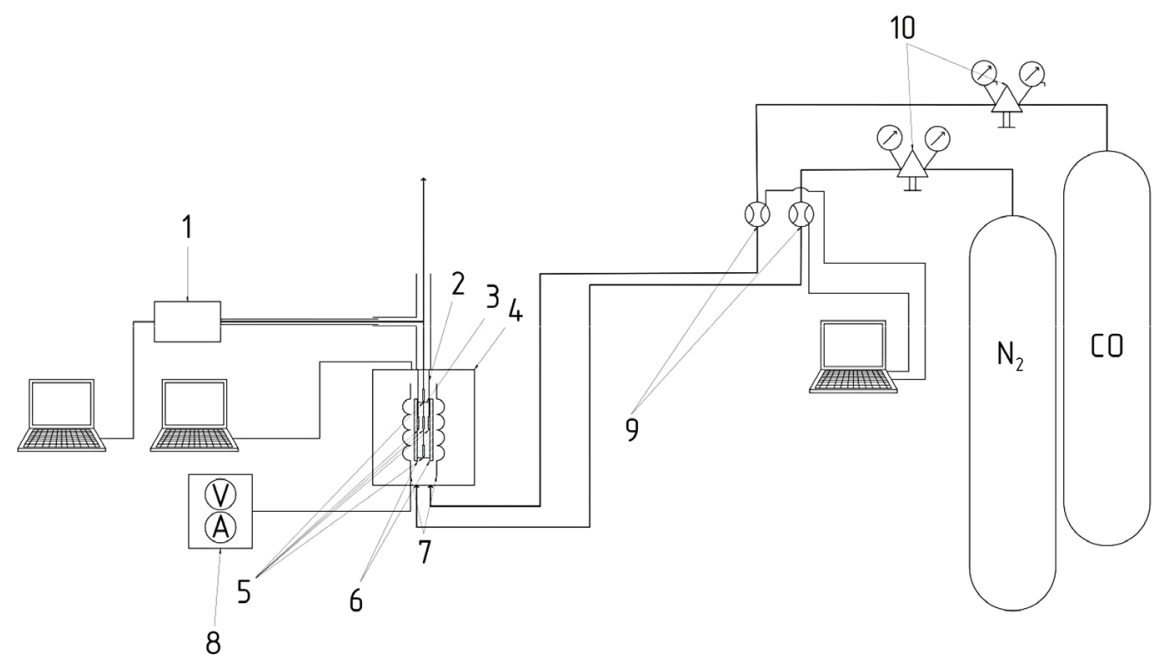

Fig. 2. Diagram of a laboratory device for studying the processes of catalytic oxidation of carbon monoxide: 1 - gas analyzer VARIO PLUS industrial analyzer MRU air fair (Germany); 2 - catalyst container made of stainless steel mesh; 3 - heating element; 4 - heat chamber; 5 - thermocouples; 6 - stainless steel pipe; 7 - ceramic pipe; 8 - temperature controller; 9 - gas flow meters; 10 - reducers

The oxidation state of carbon monoxide was calculated in accordance with the formula:

$$
X_{\mathrm{CO}}=\frac{C_{\mathrm{CO}}^{\text {in }}-C_{\mathrm{CO}}^{\text {out }}}{C_{\mathrm{CO}}^{\text {in }}} \cdot 100 \% \text {, }
$$

where $\tilde{N}_{\tilde{\mathrm{N}} \hat{I}}^{i n}-$ the mole fraction of $\mathrm{CO}$ at the reactor inlet; $\tilde{N}_{\tilde{\mathrm{N}} \hat{I}}^{\text {out }}-$ the mole fraction of $\mathrm{CO}$ at the reactor outlet.

Determination of the physicochemical characteristics of the spent catalyst for use as a red lead pigment, such as the weight fraction of iron oxide, water and volatile substances, the weight fraction of substances soluble in water, the $\mathrm{pH}$ of the aqueous extract, the weight fraction of chlorine compounds in terms of $\mathrm{Cl}$, total sulfur in terms of $\mathrm{SO}_{4}$, oil absorption, hiding power of the pigment was carried out according to the methods given in DSTU 1438-94.

\section{1. Experimental procedures}

Previous studies have established [1] that in the range of $K=0.01-3.0$ precipitation has magnetic properties. At $K>3.0$, no magnetic properties were recorded in the resulting precipitation. But 
even in this narrow $K$ range, the magnetic properties of precipitation vary rather unevenly (Fig. 3). Moreover, a stable relationship between the magnetic properties and the volume of the sediment was noted. At maximum magnetic properties, the sediment volume is minimal and vice versa. It is clear that the use of sediments obtained with a ratio of $K<0.1$ and $K>2.4$ is very problematic due to the low magnetic properties and in connection with the complication of the use of magnetic separation equipment for their removal. So, the best magnetic properties have precipitations obtained at $K=0.5$, which fully confirms the conclusions of the authors [5].

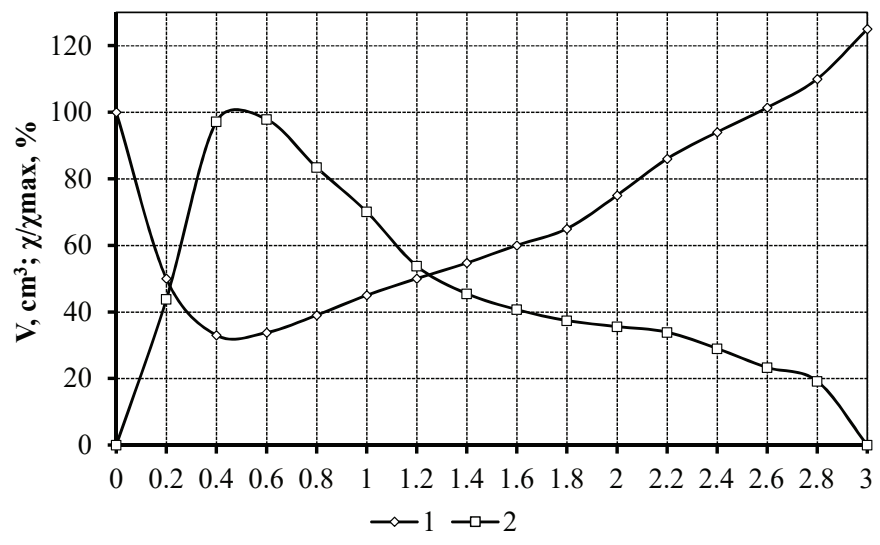

Fig. 3. Dependence of the relative magnetic properties of the magnetite deposit $1-\chi\left(\chi_{\max }\right)$ and its volume $(2-V)$ on the concentration ratio $K=\left[\mathrm{Fe}^{2+}\right] /\left[\mathrm{Fe}^{3+}\right]$

As further studies show, in the case of using ammonia at its amounts lower than stoichiometric, the precipitate does not exhibit magnetic properties (Fig. 4). An increase in the amount of ammonia leads to an abrupt growth. Moreover, a significant increase in the amount of alkali practically does not change the magnetic properties of the sediment. Thus, when obtaining magnetite by this method, the $\mathrm{pH}$ of the mixture can fluctuate within the range of 9.0-12.0, however, in real technology, these boundaries must be maintained at $\mathrm{pH}=9.0-10.0$, which is associated with the need to comply with the minimum salt content to reduce the cost of carrying out the processes of laundering magnetite. The expediency of maintaining the $\mathrm{pH}$ at this level is also justified from considerations of maintaining the total content of sulfate and chloride anions in purified iron-containing solutions at levels below the maximum permissible concentration for discharge into the sewer.

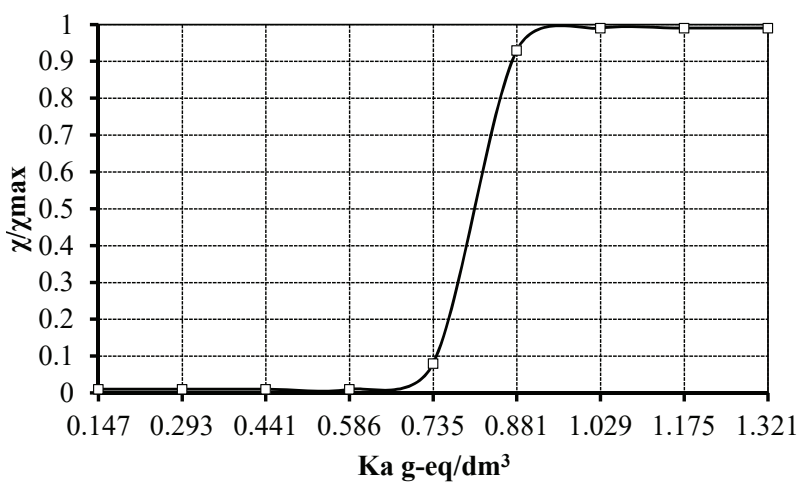

Fig. 4. Dependence of the relative magnetic properties of the magnetite suspension $\chi / \chi_{\max }$ on the ammonia concentration $K_{\mathrm{a}}$

When studying the processes of washing magnetite obtained by chemical condensation from excess salts, it was determined (Fig. 5), after washing the sediment in a fivefold amount, the mass fraction of magnetite was increased from 69.84 to $94.49 \%$, and the mass fraction of sulfate and chloride -anions decreased from 4.67 to $0.045 \%$ and 3.59 to $0.12 \%$, respectively. The pH of the solution in this case varied from 11.4 to 7.4 . 


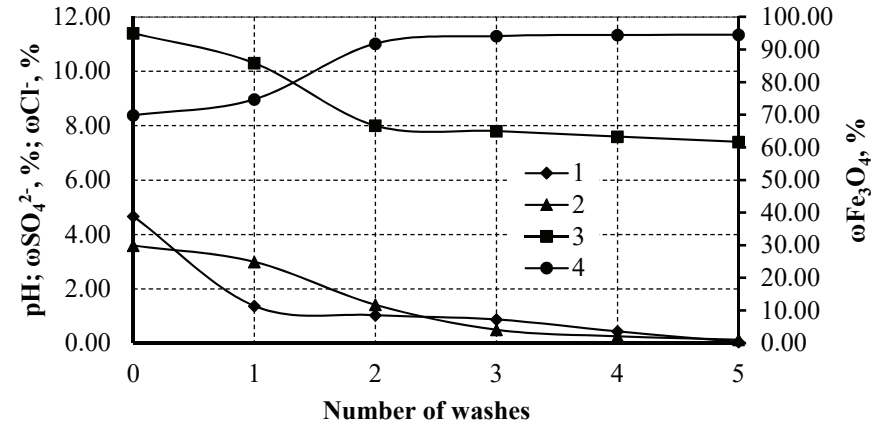

Fig. 5. Dependence of the mass fraction of sulfate anions $\omega \mathrm{SO}_{4}^{2-}(1)$, chloride anions $\omega \mathrm{Cl}^{-}(2)$, $\mathrm{pH}$ (3) and the mass fraction of magnetite $\mathrm{\omega Fe}_{3} \mathrm{O}_{4}(4)$ on the number of washes

\section{Results}

When studying the processes of catalytic conversion of $\mathrm{CO}$ into $\mathrm{CO}_{2}$ using wash from excess magnetite salts, it was determined that the oxidation state significantly depends on the rate of passage of the gas flow through the catalyst (Fig. 6). The maximum oxidation state of carbon monoxide is achieved at $400{ }^{\circ} \mathrm{C}$ and is $49 \%$.

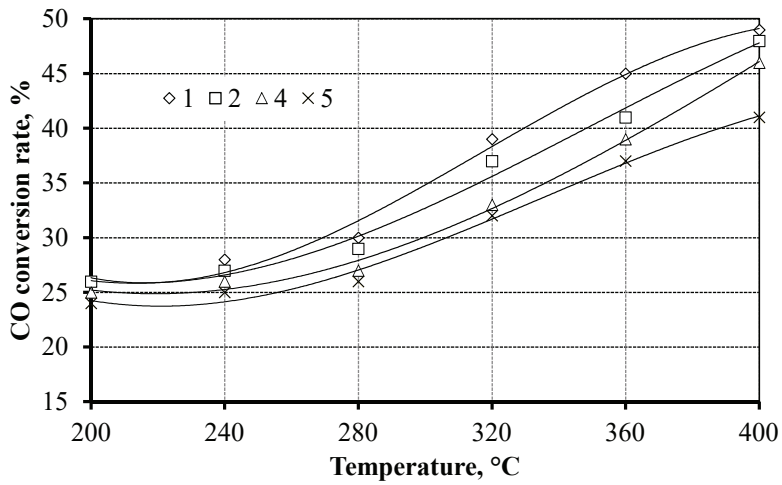

Fig. 6. Dependence of the oxidation state of carbon monoxide when using magnetite as a catalyst on temperature and volumetric gas flow rate in the range of $1,2,4,5 \mathrm{dm}^{3} / \mathrm{min}$

However, the use of magnetite as a catalyst causes difficulties from the technological point of view due to the significant energy consumption for creating the necessary excess pressure of the gas stream to pass through the highly dispersed material. As studies have shown (Fig. 7), the content of magnetite particles obtained by traditional chemical deposition with a size of 20,30 , and $40 \mu \mathrm{m}$ is 38,8 , and $4 \%$, respectively, while the increase in the size of magnetite particles upon repeated processing by the method described above was not accompanied by significant effect. After three cycles of this treatment, the content of $20 \mu \mathrm{m}$ particles decreased by $7 \%$, and the content of $40 \mu \mathrm{m}$ particles increased by $5 \%$. According to the study of the passage of a gas flow using magnetite obtained by growing, then under the same experimental conditions the increase in speed is less than $1 \%$. Therefore, taking into account the complexity of the build-up process and the additional consumption of reagents, the use of the build-up method in the processes of obtaining a catalyst for the oxidation of carbon monoxide is irrational.

When applying the method of freezing and thawing a magnetite suspension (Fig. 7), it was determined that the content of magnetite particles with a size of 20, 30 and $40 \mu \mathrm{m}$ was, respectively, 4, 30 and $7 \%$, and a significant increase in the content of particles of greater dispersion was also noted. At the same time, the indicated change in the granulometric composition of magnetite made it possible to increase the speed of the gas flow by $5-7 \%$, all other conditions being equal. 


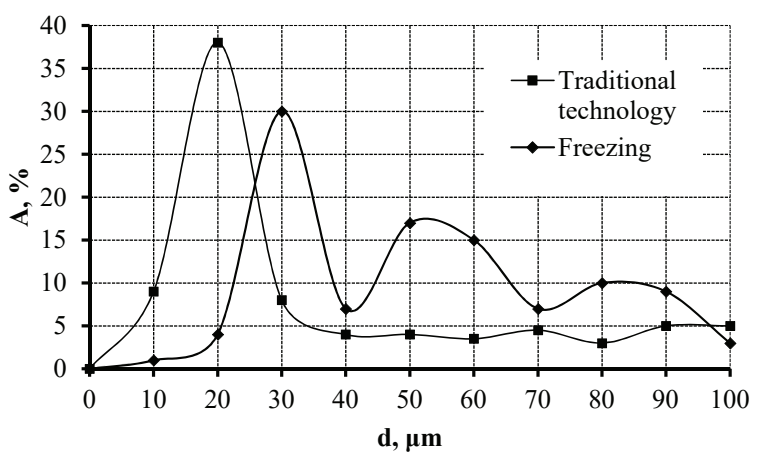

Fig. 7. Granulometric composition of magnetite obtained by the traditional method of chemical condensation and subsequent freezing

\section{Discussion}

Even in the case of an increase in the content of particles of greater dispersion, changes in the rate of passage of a gas flow through a highly dispersed material of magnetite are insignificant and can't radically affect the technological process. Unfortunately, massive iron oxides also have a small surface area, which, as a rule, does not exceed several $\mathrm{m}^{2} / \mathrm{g}$, which limits their effectiveness as catalysts for the complete oxidation of carbon monoxide [11]. An effective way to solve these problems is the nanostructuring of the active catalyst component by applying it to an inert matrix with a developed specific surface area.

Thus, for real catalytic installations, it will be more acceptable to apply magnetite on support granules with appropriate physical properties, for example, zeolite [11, 12], which will be considered in subsequent studies. As shown in [11], when deposited on microporous zeolite $\mathrm{NaY}$ iron oxides $\left(\gamma-\mathrm{Fe}_{2} \mathrm{O}_{3}\right.$ and $\left.\mathrm{Fe}_{2} \mathrm{O}_{3} \cdot \mathrm{FeO}\right)$ with a content of $0.12 \%$ at $300{ }^{\circ} \mathrm{C}$, a level of $50 \%$ $\mathrm{CO}$ conversion is achieved, and $100 \%$ occurs at $350{ }^{\circ} \mathrm{C}$.

In addition, during the industrial operation of catalysts for neutralizing $\mathrm{CO}$ gas emissions based on magnetite, emergency situations may arise due to significant changes in the composition of the gas being purified, as exemplified by a high $\mathrm{CO}_{2}$ content. In this case, the activity of the catalyst can decrease by $15-20 \%$ [13].

If to take into account that magnetite consists of $\mathrm{Fe}_{2} \mathrm{O}_{3} \cdot \mathrm{FeO}$, then the oxidation reaction of carbon monoxide using magnetite particles will be as follows:

$$
\left(\mathrm{Fe}_{2} \mathrm{O}_{3} \cdot \mathrm{FeO}\right)+\mathrm{CO} \rightarrow 3 \mathrm{FeO}+\mathrm{CO}_{2}
$$

Regeneration of the poisoned catalyst must be carried out with clean air for 4 hours at a temperature of $25^{\circ} \mathrm{C}$ with a feed rate of $1 \mathrm{~m}^{3} / \mathrm{h}$ [13] according to the reaction:

$$
6 \mathrm{FeO}+\mathrm{O}_{2} \rightarrow 2\left(\mathrm{Fe}_{2} \mathrm{O}_{3} \cdot \mathrm{FeO}\right)
$$

As studies show, when using the specified regeneration path, almost complete recovery of the catalyst activity is guaranteed and the ability to regenerate directly during operation without the need for unloading is confirmed [13]. But this technological operation leads to additional material costs for the process of catalytic oxidation of $\mathrm{CO}$.

However, in spite of the above, it can be summarized that a significant advantage of catalytic systems based on magnetite is the presence of magnetic properties, which make it easy to remove them from the reaction medium using a magnet and reuse several runs with almost no loss of catalytic activity [14].

After using magnetite as a catalyst, it is necessary to ensure its further use in the production of building materials. An expedient way of utilizing ferrite material is its use as a pigment of "red lead", since when heated in air above $150^{\circ} \mathbf{C}$, magnetite transforms into iron oxide $\mathrm{Fe}_{2} \mathrm{O}_{3}$. It was found that the characteristics of magnetite in almost most of the parameters meet the requirements of the DSTU 1438-94 standard [1]. Relatively slightly increased oil 
content (35 g per $100 \mathrm{~g}$ of "red lead") and hiding power $\left(29 \mathrm{~g} / \mathrm{m}^{2}\right)$, which is especially typical for magnetite particles without additional processing, they can be neglected, given the relative cheapness of the pigment and the simultaneous solution of environmental problems. Thus, the magnetite precipitate can be used as a pigment for the preparation of oil paints of the MA-15 type "red lead".

\section{Conclusions}

Thus, it follows from the above that magnetite is a material for complex use and can be used in a closed cycle in various environmental technologies based on:

1) the formation of high dispersion magnetic particles during the processing of pickling solutions by the ferrite method, which can significantly reduce the duration of the cleaning process, simplify it and increase the productivity of equipment. This also eliminates the need to control the course of the reaction of the formation of magnetic particles, since their characteristics are determined by the composition of the initial solutions and the conditions of their deposition;

2) the use of magnetite sediment as a cheap, affordable and effective catalyst for the oxidation of carbon monoxide from flue gases of industrial enterprises, the disposal of which after long-term use does not create problems due to its stability and inertness. By additional treatment of the magnetite sediment by washing from sulfate and chloride anions, the concentration of magnetite in the suspension is achieved, which significantly improves the physicochemical parameters of the ferrite treatment sludge. To regulate the granulometric composition of the magnetic material, along with the growth method, it is better to use the freeze-thaw process, which eliminates the additional consumption of reagents and significant environmental problems with the formation of additional wastewater;

3) placement of magnetite as a catalyst for $\mathrm{CO}$ oxidation in containers of rectangular cross-section in the firing channels of furnaces for firing electrodes in chambers heated by flue gases;

4) utilization of magnetite in the manufacture of building materials as a pigment in the preparation of oil paints such as MA-15 "red lead", which is confirmed by compliance with most of the indicators to the requirements of the DSTU 1438-94 standard. Due to the slightly increased oil content and hiding power, which is especially characteristic of magnetite particles without additional processing, they can be neglected, given the relative cheapness of the pigment and the simultaneous solution of environmental problems.

Thus, it is possible to summarize that the innovative technological product of this work is a fundamentally waste-free technology for processing pickling solutions by the ferrite method with the formation of a product with magnetic and catalytic properties, the further processing of which is used in the production of building materials. The ecological feasibility of creating such an innovative product is due to the possibility of widespread introduction into industrial production.

\section{References}

[1] Radovenchyk, V. M., Ivanenko, O. I., Radovenchyk, Ya. V., Krysenko, T. V. (2020). Zastosuvannia ferytnykh materialiv v protsesakh ochyshchennia vody. Bila Tserkva: Vydavnytstvo O. V. Pshonkivskyi, 215.

[2] Tekhnologiia ochistki stochnykh vod ot ionov tiazhelykh metallov metodom ferritizatsii. Available at: http://www.aquapromspb.ru/vou/reagentnaya-obrabotka Last accessed: 25.10 .2020

[3] Lou, J.-C., Chang, C.-K. (2006). Catalytic Oxidation of CO Over a Catalyst Produced in the Ferrite Process. Environmental Engineering Science, 23 (6), 1024-1032. doi: http://doi.org/10.1089/ees.2006.23.1024

[4] Ivanenko, O. I., Nosachova, Yu. V., Overchenko, T. A., Nakonechna, M. V. (2020). Features of the use of catalysts of various types in the processes of neutralization of carbon monoxide of flue gases. Proceedings of the NTUU "Igor Sikorsky KPI”. Series: Chemical Engineering, Ecology and Resource Saving, 1 (19), 22-42. doi: http://doi.org/10.20535/26179741.1.2020.207808

[5] Kunevich, A. V., Podolskii, A. V., Sidorov, I. N. (2004). Ferrity: Entsiklopedicheskii spravochnik. Magnity i magnitnye sistemy. Vol. 1. Saint Petersburg: Izdatelstvo «Lik», 358.

[6] Betekhtin, A. G. (2007). Kurs mineralogii. Moscow: Knizhnii dom "Universitet”, 721. 
[7] Petrakova, A. V., Urusov, A. E., Kostenko, S. N., Pridvorova, S. M., Vasilev, M. A., Zherdev, A. V. (2013).Sintez magnitnykh nanochastits oksida zheleza dlia primeneniia v immunoanalize. Sovremennye problemy nauki i obrazovaniia, 5. Available at: http://www.science-education.ru/ru/article/view?id=10559 Last accessed: 25.10.2020

[8] Hyeon, T. (2002). Chemical synthesis of magnetic nanoparticles. Chemical Communications, 8, 927-934. doi: 3http:// doi.org/10.1039/b207789b

[9] Dikanskii, Iu. I., Zakinian, A. R., Konstantinova, N. Iu. (2008). O magnitnoi pronitsaemosti magnitodielektricheskoi emulsii. Zhurnal tekhnicheskoi fiziki, 78 (1), 21-26.

[10] Radovenchik, Ia. V., Romanenko, M. I., Radovenchik, V. M. (2017). Zalizomistki sorbenti dlia ochischennia vodi vid naftoproduktiv. Ekologiia i promyshlennost, 1 (50), 74-80.

[11] Akhlebinina, A. A., Moskovskaia, I. F., Iuschenko, V. V., Romanovskii, B. V. (2006). Kataliticheskoe okislenie metanola na vysokodispersnom okside zheleza v mikro- i mezoporistykh molekuliarnykh sitakh. Zhurnal fizicheskoi khimii, 80 (1), 72-76.

[12] Ivanenko, O., Gomelya, N., Panov, Y., Overchenko, T. (2020). Technical solutions for reducing emissions of carbon monoxide with flue gases of furnaces for baking electrodes. Bulletin of the National Technical University «KhPI». Series: New Solutions in Modern Technology, 3 (5), 45-52. doi: http://doi.org/10.20998/2413-4295.2020.01.07

[13] Petrov, A. Iu., Sinitsin, S. A. (2014). Kataliticheskaia detoksikatsiia dymovykh gazov v neftepererabatyvaiuschei promyshlennosti. Tekhnologiia nefti i gaza, 2 (91), 18-23.

[14] Kharisov, B. I., Dias, H. V. R., Kharissova, O. V. (2019). Mini-review: Ferrite nanoparticles in the catalysis. Arabian Journal of Chemistry, 12 (7), 1234-1246. doi: http://doi.org/10.1016/j.arabjc.2014.10.049 